\title{
Multi-hazard analysis and design guidelines: recommendations for structure and infrastructure systems in the Indian context
}

\author{
Tathagata Roy and Vasant Matsagar*
}

The interdependencies between various risks imposed by natural as well as accidental/man-made hazards demand a holistic design approach to ensure structural safety through multi-hazard engineering. In this regard, the present article provides guidelines and recommendations for design of structure and infrastructure systems under multi-hazard scenarios of natural and accidental/manmade hazards, specifically in the Indian context. The need and relevance of multi-hazard analysis and design of structures are elaborated, and key design strategies during design (service) life for normal civil engineering structures as well as critical infrastructure and facilities are recommended for major regions of India experiencing multiple hazards.

Keywords: Design guidelines, multi-hazard analysis, natural and man-made hazards, structure and infrastructure systems.

MULTI-HAZARD engineering is a relatively new concept in civil-structural engineering that deals with loss estimation of different portfolios of structure and infrastructure systems located over an extended geographical area and subjected to multiple natural or accidental/man-made hazards. A multi-hazard approach considers more than one hazard at a given location that takes into effect the possible interrelations between these hazards, including their simultaneous or cumulative occurrence and their potential interactions. Being one of the 10 most disaster-prone countries of the world, India experiences both natural as well as accidental (technical)/man-made hazards, which are initiated most likely due to geoclimatic conditions, topographic features, environmental degradation, population growth, urbanization and industrialization, and nonscientific/non-engineered development practices. Over 25 states and Union Territories (UTs) out of the 36 have been experiencing more than a single natural hazard such as earthquakes, winds/cyclones, floods, droughts, landslides and avalanches, and forest fires for several decades ${ }^{1}$ (https://nidm.gov.in). According to the National Disaster Management Plan (2019), almost 58.6\% of the total area of the country is prone to earthquakes of moderate to very high intensity. More than $75 \%$ of the total coastline is prone to gusty wind/ cyclones and tsunamis, whereas $\sim 12 \%$ of the land is prone to floods and river erosion $^{2}$ (https://ndma.gov.in). In addition to the natural

The authors are in the Multi-Hazard Protective Structures (MHPS) Laboratory, Department of Civil Engineering, Indian Institute of Technology (IIT) Delhi, Hauz Khas, New Delhi 110 016, India.

*For correspondence. (e-mail: matsagar@civil.iitd.ac.in) disasters, technological/man-made disasters that are caused by chemical, mechanical, civil, electrical or other process failures due to accident, negligence or incompetence have resulted in intense consequences, wherein 130 such incidents have been recorded from 2002 to 2010 in more than 15 states and UTs in India. Moreover, the threats induced by natural hazards have been ranked fourth among the possible 12 threats looming in the country, according to India Risk Survey ${ }^{3}$, whereas terrorism and insurgency is ranked second and fire hazard is ranked fifth. These numbers are quite alarming in the Indian context, where the economy is growing by leaps and bounds compared to other larger/populous countries in the world. In this regard, preparedness and response mitigation strategies for the ever-existing multiple hazards must be devised for site-specific and scenario-based risks, wherein viable holistic technological solutions are required to be developed and implemented in order to build resilient structure and infrastructure systems against such multiple hazard scenarios.

\section{Multi-hazard demography of India}

There is undeniably a varied degree of vulnerability in almost every region of India when it comes to structure and infrastructure safety under a combination of different multiple natural and/or accidental/man-made hazard scenarios. In Appendix 1, a detailed list of the multi-hazard regions in India is shown as reported by the Bureau of Indian Standards (BIS) in the National Building Code (NBC) of India ${ }^{4}$. The unique geoclimatic as well as 

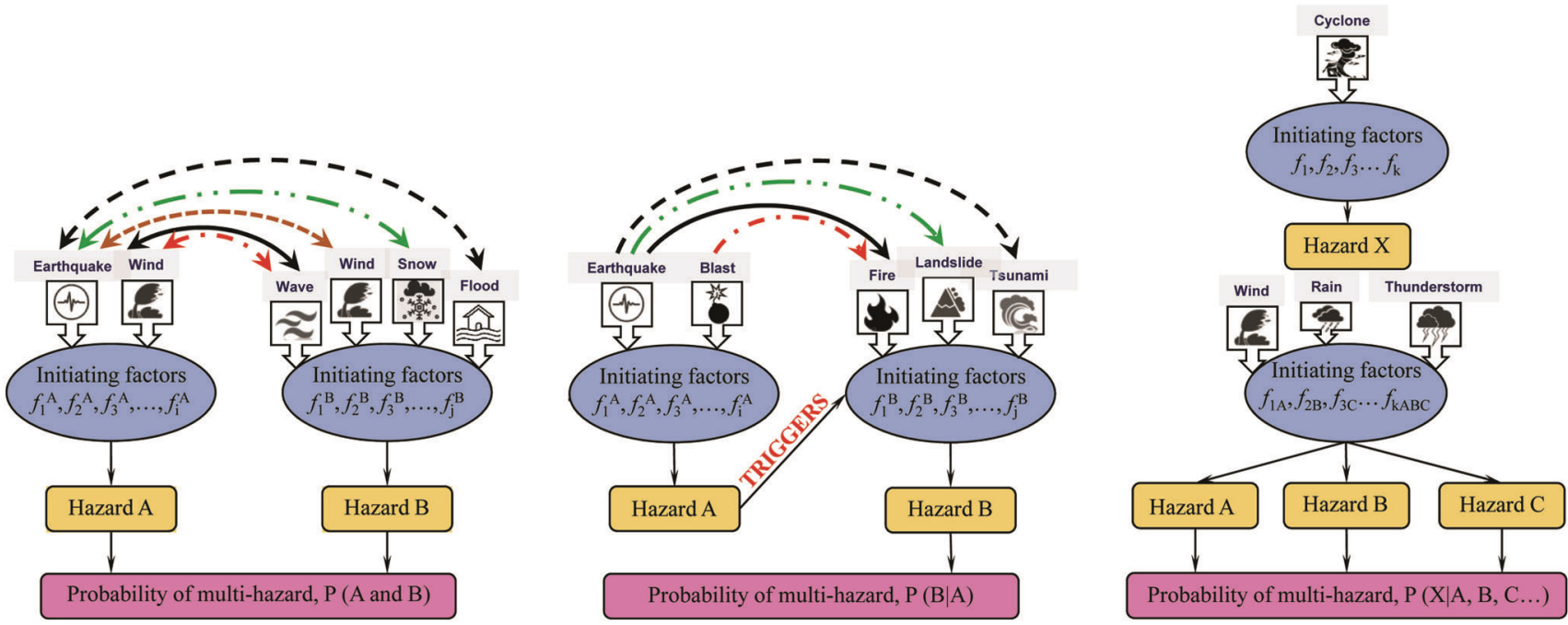

Figure 1. General classification and probability of occurrence for multi-hazard scenarios.

socio-economic conditions existing throughout the year accelerate the intensity and frequency of the disasters, thereby causing devastating failures of different structural systems and disruption of life-support system in the country.

Overall, India can be demarcated into four distinctive regions based on type of exposure to risks from natural hazards, which in turn affects the socio-economic stability of the exposed regions. These regions can be categorized as: (i) the Himalayan region (earthquake, cascaded landslide, snowfall and avalanches and/or gusty/cyclonic wind), (ii) the Great plains of alluvial deposits (earthquake, cascaded landslide and flood erosion), (iii) hills of peninsular India (earthquake, cloudburst/rainstorm, and/or gusty wind) and (iv) the coastal zones (cyclone, storm, wave, gusty wind, and/or tsunami $)^{5}$. Moreover, with substantial increase in urbanization and globalization, the risks induced by the accidental/man-made hazards have grasped almost the entire Indian state, and particularly in the industrial towns. Overall, the combination of different multiple hazards may be distributed into several categories, such as simultaneous and correlated (e.g. wind and surge), simultaneous and uncorrelated (e.g. earthquake and snow), non-simultaneous and uncorrelated (e.g. earthquake and wind), and cascading and correlated (e.g. fire following earthquake/blast; Figure 1). In such cases, the occurrence of hazards must be dealt with different probabilistic techniques.

\section{The Himalayan belt}

The trans-Himalayan belt is extremely prone to earthquakes due to the subduction zone, which has triggered landslides at a considerable rate (e.g. Bihar-Nepal earthquake, 1988; Uttarkashi earthquake, 1991; Sikkim earth- quake, 2015, etc.). The Himalayan belt is designated as seismic zone $\mathrm{V}$ by the Bureau of Indian Standards, IS 1893 - Part 1 (ref. 6), which experiences the highest seismic intensity and is the most active seismic zone. The belt comprises the whole of North East India, the northern portion of Bihar, Uttarakhand, Himachal Pradesh, and Jammu and Kashmir. These regions have highly populous cities, and construction practices in them are predominantly not earthquake-resistant. Moreover, about 30\% of the global landslides occur in the Himalayan belt, and in this regard, the history of landslides occurring here is unique and has no comparison with any other mountain range in the world ${ }^{1}$. Likewise, these regions tend to experience high gusty wind as well as cyclonic windstorms, as observed in the wind and cyclone map of India (https://nidm.gov.in) ${ }^{1}$. Therefore, the extent of occurrence of such events in these regions (Figure 2), cannot be overlooked, which calls for multi-hazard assessment strategy for building resilient structure and infrastructure systems (Figure 2).

\section{The Great plains of alluvial deposit}

The alluvial plains comprise adjacent areas of the Indus, Ganga and Brahmaputra, which extend approximately $3200 \mathrm{~km}$ from east to the west of Indian peninsula ${ }^{1}$. Being the extension of the Himalayan ranges, geotectonic features are predominant in the alluvial plains that make the region susceptible to earthquakes, landslides and flooding with erosions either due to heavy downpour or snow melting. Major areas prone to such risks are the plains of Assam, Bihar, Uttar Pradesh, Punjab and Haryana. In this scenario, the soil is mostly eroded under the action of flowing water, which results in scouring around and under the foundations that result in uprooting 
of foundation systems (e.g. bridge piers) of the critical infrastructure systems. In addition, as discussed, this region is also fairly prone to seismic activities; hence, the combined effects of scouring and earthquake substantially increase vulnerability and risk, which calls for developing holistic multi-hazard structural assessment strategies.

\section{Hills of peninsular India}

Peninsular India comprises parts of Gujarat, Maharashtra, Goa, Karnataka, Kerala, Tamil Nadu, Andhra Pradesh and Telangana ${ }^{1}$. Although it is considered to be the most stable region in the Indian subcontinent, occasional earthquakes in this region indicate movements of geotectonic plates underneath (e.g. 1993 Killari earthquake). Moreover, due to severe downpour along with frequent winds, the stable peninsular region is also under the grip of multi-hazard events such as earthquake, gusty wind and rainfall. Flood-induced calamity of a severe nature occurred in Maharashtra (Mumbai) and Kerala in 2005 and 2018 respectively causing extensive loss of life and property. The flood-instigated havoc recurred in Maharashtra in 2019. Therefore, it becomes important to characterize the hazard scenarios and develop integrated framework under these multi-hazard scenarios, which are specific to the region concerned.

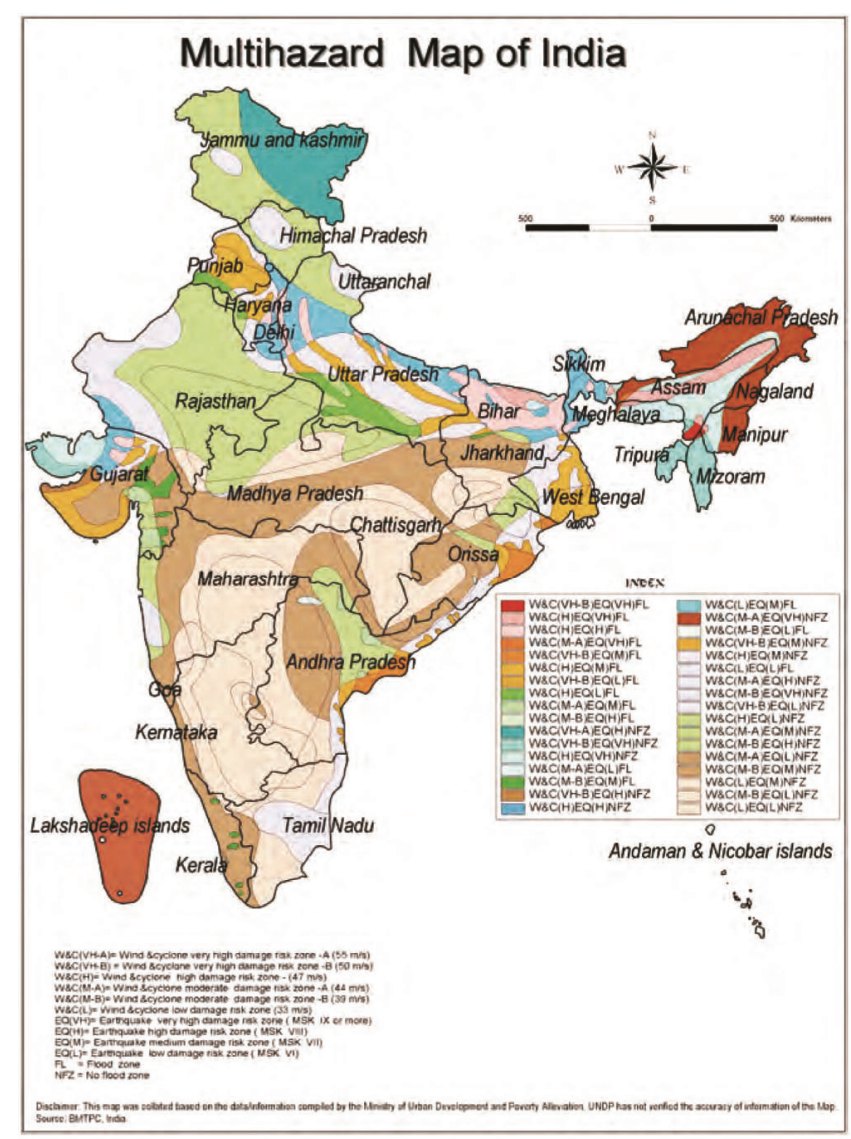

Figure 2. Multi-hazard zoning map of India ${ }^{30}$.

\section{Coastal zones}

The distinct natural hazard affecting the coastal regions of India is the cyclone that initiates gusty winds, storm surges and waves. Nearly $10 \%$ of the tropical cyclones occurring around the world mark their landfall on the coastlines of India. Around $71 \%$ of the total coastlines is located in 10 states, viz. Gujarat, Maharashtra, Goa, Karnataka, Kerala, Tamil Nadu, Puducherry, Andhra Pradesh, Odisha and West Bengal. Some of the recent devastations demonstrate that the susceptibility of these areas to cyclones and storms triggering severe gusty winds, heavy rainfall, storm surges, liquefaction and river floods is more pronounced, especially in the northern part of the Bay of Bengal, where the speed of the cyclones can reach up to $165 \mathrm{~km} / \mathrm{h}$. Moreover, the movements of geotectonic plates (e.g. India-Australia-Capricorn tectonic plate) on the ocean floor results in earthquake-triggering tsunami events in the coastal region (e.g. 2004 Indian Ocean earthquake and tsunami). Therefore, in these regions, the multi-hazard situations demand proper redressal in order to ensure safety, sustainability and resilience of the built environment.

Apart from the unique geo-climatological features causing different hazards throughout the year, India's steady growth in economy has also triggered various technological/man-made risks in terms of accidents in industries, terrorism, and potential consequences of fire. Therefore, it is important to understand the complexity of such risks, apart from natural hazards, from accidental/man-made hazards as well from the viewpoint of the spectrum of stakeholders, i.e. design engineers, policymakers, corporations and individuals of the civil society with the purpose of making the structure and infrastructure systems disaster-resilient, and reduce loss of life and assets during extreme events.

Responding to the biggest threats of India, it is important to mainstream and integrate disaster risk reduction within and across all sectors through multiple hazard mapping (MHM). In this context, the Sendai Framework for Disaster Risk Reduction (SFDDR; 2015-30) outlines different priorities for action to prevent new and reduce existing disaster risks, in order to enhance disaster preparedness to 'build back better' in recovery, rehabilitation and reconstruction. The developed MHM framework should help in analysing the impact on the built environment through different risk reduction and retrofitting techniques for improving the resilience of the built environment. A typical case study for multi-hazard vulnerability of Gangtok, East Sikkim, has been conducted by the National Disaster Management Authority (NDMA), which dealt with earthquake, landslide, flashflood, drought, snow and avalanches. Hence, the accuracy and content of an MHM framework is always greater than the individual hazard information for a given region. Since India has been traditionally vulnerable to different disasters on 
account of its unique geo-climatic and environmental conditions, NDMA has suitably brought out more comprehensive national disaster mitigation plans to cover additional multi-hazard disasters and adding new dimensions of sustainable development and climate change. Such mitigation and risk reduction initiatives should result in decreased requirements in response, efforts and eventually in saving loss of life and property.

\section{Multi-hazard assessment strategies and design recommendation for India}

There is substantial exposure of structures to vulnerability and risk from multiple hazards in almost all major regions of India (Figure 2). With rapid urbanization, industrialization and globalization and due to multiple hazards, structures constructed in these regions have a high chance to experience catastrophic failure under other natural/accidental hazards. This is because the current Indian Standard (IS) design philosophy in general considers design of structures under multiple hazards primarily using load combination approach ${ }^{6}$. During the service life, ageing of structural elements takes place whereby their load-carrying capacity reduces. Such degradation in resistance is also likely under ambient loads imposed for longer duration. The resistance factors considered at the design stage for the structural elements, therefore, become inapplicable during the service life, especially in the later stage. In this regard, structural engineers will design a new structure using the worst load combination by considering different loads imposed, for example, that arising from earthquake or wind with appropriate load factors. Hence a structure critically designed for earthquakes might induce significant forces under wind hazard, thus causing its possible failure, if not designed adequately for two distinct demands. For example, lightweight materials used in the construction of different structural systems may serve as an effective design strategy during earthquakes, as heavier structures are more vulnerable under the earthquakes attracting higher inertial forces. However, the use of lighter materials, which attract reduced seismic forces, may bring catastrophic consequences under cyclonic and gusty winds, thereby endangering the socio-economic stability. Similarly, heavier structures are preferred in blast-resistant design unlike that in earthquake-resistant design. Besides, in hilly terrain, more than $20 \%$ losses under low to medium earthquakes are attributed to landslides alone. The triggered landslides have affected well-constructed structures as these are adversely located on the ground. Therefore, in case of constructing new structures and upgradation of existing ones, the design decisions will essentially have to be based on predominant multi-hazard scenarios existing at the location or site of interest, so that the constructed facility remains safe in the entire design (service) life under the considered hazard scenarios, and particularly with adequate lifecycle factor of safety (FOS).

Although it is crucial to address the possibility of occurrence of multiple hazards as applicable to an area, it may not always be economically viable to design all the structures for multiple hazards. Special structures of importance, e.g. nuclear power plants, hydroelectric power stations, and lifeline structures, such as hospitals, schools, bridges, water supply tanks and allied facilities as well as emergency rescue shelters may be essentially designed for multiple hazards due to their strategic importance in civic life than economic feasibility. In such scenarios, site-specific data need to be collected, and the design should be necessarily carried out based on some accepted levels of risk from anticipated hazards during design life of the structure or infrastructure system. The factors that must be considered in determining such risks are: (a) The severity of the hazard characterized by intensity in case of earthquakes, duration, and velocity in the longduration gusty winds/storm, rate of scouring in floodprone areas and amount of combustibles in a given area for triggered fire hazards (fire load density). (b) The frequency of occurrence of severe multiple hazards with their appropriate return periods, and simultaneous or cascading characteristics during the design life of the structure.

Since, in most cases the current IS design guidelines do not necessarily recommend holistic consideration of different hazards, the multi-hazard assessment strategy needs to be integrated initially using several prescriptive approaches, wherein special/important structures may be designed for multiple hazards using the historical data and experience, which can be obtained for a given site and using the available code provisions for consideration of the loads. Figure 3 presents a generic technical framework that accounts for holistic consideration of multiplehazard scenario relevant to structural engineering. The hazards here have been differentiated based on their dependency, which is the main highlight of the assessment technique. For example, non-correlated earthquake and wind will have a different assessment scheme compared to correlated earthquake and scour hazards.

\section{Design recommendations for earthquake and gusty wind/cyclone}

Undeniably, earthquakes and gusty winds/cyclones are considered to be non-simultaneous and uncorrelated hazards, wherein probability of occurrence of both together is approximately zero. In such cases, the existing assessment strategy may undermine the level of risk induced in any structural system (e.g. building, long-span bridge etc.), as the structure designed for a particular hazard (earthquake) is observed to fail another hazard (gusty 


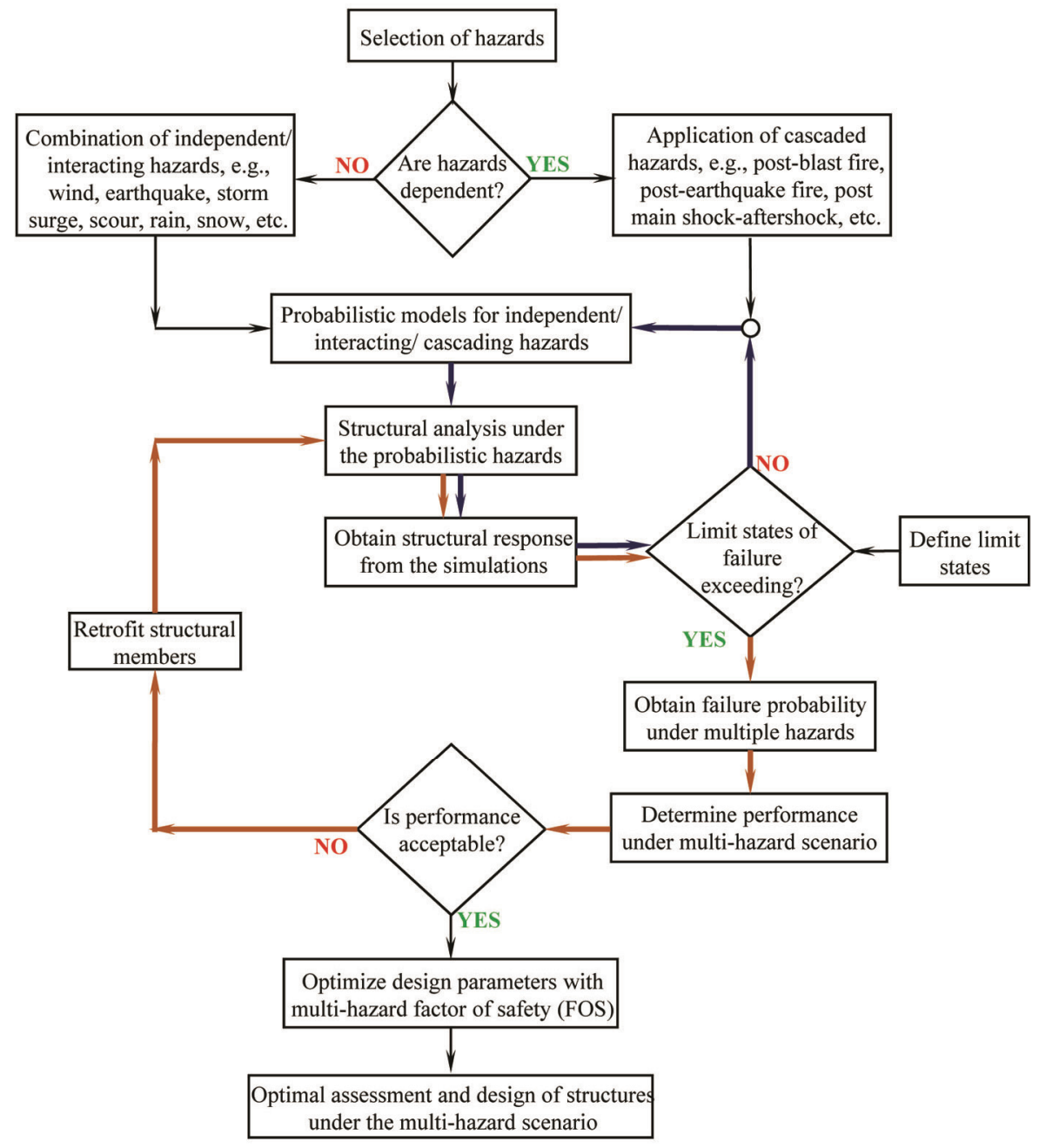

Figure 3. Technical framework for optimal assessment of structures under multiple-hazard scenarios in entirety.

wind) ${ }^{7}$. In such cases, it becomes important to characterize the structure from its modal properties to begin with for assessing if frequency matching may take place with the dynamic excitations.

As reported by Roy and Matsagar ${ }^{8}$, structural systems having fundamental frequencies especially ranging from $0.25-0.5 \mathrm{~Hz}$, need to be explicitly designed for multihazard scenarios of earthquake and wind. The study demonstrated that multi-hazard design decisions arise when modal frequencies of structures are dominated by both seismic and wind hazards. Furthermore, the effectiveness of passive response control systems was highlighted under multi-hazard scenarios of earthquake and wind. The control devices employed with additional damping characteristics (e.g. viscous damper, viscoelastic damper, base isolation, etc.) help in response reduction under the seismic action, whereas the devices employed with additional stiffness (e.g. steel bracing) significantly reduce response under the action of the wind loads. Moreover, passive control devices with additional damping have limited performance under the multi-hazard scenario. Hence, selection of any control device for response mitigation under such scenario is crucial as such a device has shown to have beneficial effects for one hazard and detrimental effects for another hazard. Moreover, structural vulnerability in high-amplitude seismic and gusty wind zone during the design life varied largely for different damper schemes. The capacity of passive control devices such as base isolation systems, steel dampers, viscous or friction dampers and similar dynamic response modification devices designed for important structures, needs to be checked for their performance and effectiveness under the multi-hazard scenarios prevalent at a specific location/ site $^{9}$. This is essential because the control devices are customarily designed based on a single hazard, which may not be suitable and effective under the multi-hazard scenario $^{7}$. Hence, for such multi-hazard scenarios, the following design guidelines are recommendable:

(a) Structure and infrastructure systems such as highrise buildings, long-span bridges, cable-stayed bridges, 
liquid-containing/retaining structures, pipelines carrying sensitive fluids, industrial infrastructure and similar special/important facilities must be designed for scenariobased natural and accidental multiple hazards for sitespecific conditions.

(b) For dynamically excited structures, matching of modal frequencies with excitation frequency components must be checked and the design must ensure that there is no adverse response from the modal resonance.

(c) Selection of proper response modification devices, passive/active control schemes based on site-specific conditions and probability of occurrence of each hazard and to strategize their design adequately catering to multihazard scenarios pertinent to the case.

\section{Design recommendations for earthquake and flood}

Bridge infrastructure systems serve as the lifeline structures that may be severely affected under design earthquake and flood hazards, which can be considered as independent and concurrent events. The currently applicable IS design specifications are based on design limit states calibrated mainly for earthquake-induced load, with some fractions of dead load and frequent live load ${ }^{10}$. A bridge must remain in serviceable condition under design earthquake so that the transportation network remains functional after any extreme event for effectively carrying out rescue and rehabilitation operations, apart from maintaining supplies. Bridges are an integral part of the surface transport network and appropriately considered as lifeline structures. While considering the seismic safety of bridges in earthquake-prone regions, the design of substructure or foundation system must incorporate the scour effect; however, the hazard effect is simply considered to be an equivalent hydrodynamic force. In such cases, although scour is an extreme hazard effect, estimation of the scour effect is capacity-based; whereas the seismic effect is force-/displacement-based approach. When the frequently applied loads (gravity and moving loads) are combined with infrequent extreme hazard loads (scour and earthquake), the limit-state-based methodology recommended in the codes/standards cannot be readily used for the multi-hazard design strategies ${ }^{11-15}$. Another major limitation in the current design code is that the hydrodynamic force is considered up to the mean scour depth level, whereas several studies have shown that critical scour depth is essential for seismic assessment of bridges located in the regions under earthquake and flood hazards ${ }^{16,17}$. Moreover, with washing away of the riverbed material due to scouring effect, the effective length of the bridge pier increases, thereby attracting larger forces under the action of seismic effects. Hence, considering all these effects, we recommend the following: (a) Treat flood scouring in bridge design as an extreme hazard effect and introduce relations for scour calculations based on return period of flood discharge in a region of particular interest. (b) Introduce critical scour depth in design calculations to avoid over-conservative scour calculation methods under a design flood event.

\section{Design recommendations for earthquake, flood and gusty wind}

Andhra Pradesh, Assam, Gujarat, Kerala, Odisha, West Bengal, and Puducherry) are exposed to flood, cyclone, and seismic risk ${ }^{2}$. In these regions, storm surges of substantial height generally occur with a cyclone, especially in the $10-15 \mathrm{~km}$ wide coastal belt, which constitutes a serious hazard in addition to high gusty wind speeds. Although it is unusual to expect simultaneous occurrence of these hazards, in any case buildings and important infrastructure are required to be designed for the multihazard scenario in order to have adequate resistance and FOS against all the hazards and ensure their performance according to the design requirements. In this case, it is recommended to integrate the design strategies provided earlier in the text.

\section{Design recommendations for cascading post-explosion/blast fire}

Design of structures against terrorism has been an escalating concern essentially in reducing the damage to structure and infrastructure systems against such threats in the current socio-political scenario. Explosion or blast event followed by fire or post-blast fire (PBF) is a causeand-effect phenomenon of such acts of terrorism causing catastrophic failure of structures through intricate cascading effects. Industrial disasters related to explosions have been observed in the Bhopal Gas Tragedy (1984), Mayapuri Radiological Incident (2010), Vizag Gas Leak (2020), and similar catastrophes during other blast events, not many of which have been reported. Moreover, the lifeline structures such as bridges, due to their unique strategic value and serious impact on civic life, have become vital targets of terrorist attacks and military strikes. Hence, the safety of these structural systems against extreme blast and fire loads during the expected service life has been a crucial research topic ${ }^{18}$. With increasing global terrorism threats, potential clients have started to focus on protection against sabotage, as can be observed for the Kosciuszko Bridge in New York, USA, where blast and fire safety were required for efficient protection against fire as well as a wide array blasts and sabotage ${ }^{19}$. The existing design code and guidelines do not consider the cascading effects on the structural systems, wherein prescriptive approaches are followed for designing individual blast-resistant structures ${ }^{20,21}$ and prescribed reinforcement cover for a given structural 
member size in the case of fire hazard ${ }^{22}$. However, in such cascaded scenarios of multiple hazards, the damage experienced due to successive effects of blast and fire is not equal to the sum of the damage induced individually by blast or fire hazard. Thereby, the cascaded damage entirely depends upon the degradation caused initially by the primary hazard. The degradation induced depends on the sole behaviour of the materials used in the construction of the structure and the structural system. In such cases, to begin with, prescriptive PBF resistance factors need to be proposed which should be used to multiply member capacities under the succeeding fire load for reducing capacity of the structural members due to damage caused by the preceding hazard, blast in this case. The factor should act as a function of intensity of blast and subsequently to ensure extinguishing of fire evacuating time, or fire rating the design of the structural elements for exposure requires appropriate load and resistance factors. Moreover, for the design forces (demand) in both case, the preceding event, blast as well as succeeding event, fire load factors are required to be proposed which should be used to multiply both the demands, wherein fire demand is a function of intensity of blast. For example, duly considering such interdependencies between demands and capacities under the multi-hazard cascading scenario of $\mathrm{PBF}$, the fire resistance of reinforced concrete (RC) wall panels decreased by up to $\sim 25 \%$ under the cascaded fire hazard scenario after considered blast event ${ }^{23}$.

\section{Evolution of design codes: probability-based multi-hazard engineering}

In India, classical design philosophy in structural engineering started with the working stress method (WSM) approach, which was mainly based on limiting permissible stresses in the structure when subjected to worst combination of loads. The main drawback of the deterministic WSM approach is that the effects of uncertainties in the loads and resistance are completely disregarded. Thereby, desired FOS in the designs may not be actually achieved. The design philosophy was replaced by the limit state method (LSM) approach, wherein the design of structural elements is based on partial safety factors for loads and resistance. Moreover, the LSM approach suitably addresses the limit states of strength and serviceability. The load and resistance factors used in the LSM design approach are derived based on the probabilistic approach, thereby providing a more rational and scientific design procedure. Two limit states are prescribed in the IS for gravity load design, which are of serviceability and collapse $^{24}$. According to the seismic design provision ${ }^{6}$, only a single limit state exists that corresponds to mostly 'slight damage' prescribed by the HAZUS ${ }^{25}$. With increased expectation of performance level from the clients (e.g. builders, developers), there has been an urge to shift to performance-based design (PBD) approach for structural systems that are to be designed for different performance levels under a given hazard scenario. The PBD approach utilizes probability of occurrence of the concerned hazard at a given site, how the structural elements perform under varying intensities of the loading, along with the uncertainty in material as well as geometric properties to estimate the structural vulnerability and its associated risk. For example, the performance level of a school or office building is typically different from that of a military structure or a nuclear facility, wherein it is expected that the overall damage in such critical structures is very low, if not zero, under the anticipated design forces. To our understanding, the evolution in the design philosophies has thus far been based merely on single hazard framework. However, it has been shown that the probability of exceeding a limit state under multi-hazards could increase multifold compared to that under only a single hazard ${ }^{26}$. Roy and Matsagar ${ }^{8}$ have studied the effectiveness of different archetype buildings, wherein they advised the use of joint probability of failure to estimate the increased failure probability of buildings under multi-hazard scenarios of earthquake and wind. Such advancements in the analysis and design procedure should be imminent to have reliable and robust societies against different multi-hazard scenarios.

With ever-increasing effects of climate change worldwide and particularly in India, and in addition to frequent seismic activities, the reliability of infrastructure systems, especially bridge structures, is now of serious concern. The conjunctive effects of earthquakes and floodinginduced scour necessitate the use of integrated probabilistic approach due to the degree of inherent uncertainties. Several challenges exist in developing such integrated analysis frameworks, such as the hazard interaction problem between seismic and flood-induced scour effects, which is fundamentally difficult to model due to unavailability of concurrent hazard models and lack of site-specific data. Moreover, the current assumption in probabilistic design of infrastructures does not consider rare multi-hazard events (e.g. earthquake, rainstorm, flood-induced scour, and blast/fire effect) that are at the tail end of the probabilistic hazard curves. Such multihazard events are required to be codified and coherently accounted for in the hazard characterization ${ }^{27}$.

Until now, analysis and design of structures under low probability-high consequence (LPHC) blast/fire/manmade hazards have by far been deterministic in nature, e.g. using different thicknesses of concrete cover for achieving fire rating/resistance. As the physical properties of the structural system, such as dimension of structure, capacity of structural material, etc. as well as the loading phenomena invariably fluctuate, the current simplified design approaches are found to be relatively less rational. Owing to higher degree of uncertainties in 
structural parameters as well as blast/fire load or equivalent load occurring due to any man-made hazard, predicting the performance of structures under explosion loads involves extreme difficulties and challenges ${ }^{19}$. Moreover, material behaviour and the subsequent structural response under such extreme technological hazard possess a larger degree of nonlinearity as well as stochasticity, which become important in determining the reliability of a structure and infrastructure system, not only at its design stage but also during service life. In this context, it is imperative to address the challenges concerned with definitions of uncertain loadings and structural details through proper stochastic multi-hazard frameworks, thereby improvising the design guidelines to make robust blast- and explosion/fire-resistant civil structures.

To summarize, the development of multi-hazard analysis and design approaches requires foresight and an in-depth understanding to outline the interaction and inter-relation effects through efficient probabilistic frameworks for evaluating the consequent risks for structures. The type, probability of occurrence and expected intensity levels of the hazards and their subsequent impacts on the structural systems in design (service) life may vary for different hazards. Hence, the material properties used for initial design iterations are expected to change under any given hazard, which should alter the performance of the structure under subsequent events in the service life of the structure. In such cases, the final load and resistance factors also tend to change from the values that were initially calculated for the single hazard scenario according to the contemporary design philosophy. Therefore, it is pertinent to introduce new 'multi-hazard lifecycle load and resistance factors that incorporate multi-hazard lifecycle degradation (due to ageing, carbonation, corrosion, ambient vibration and effects of different actions, agents, and hazards) under multiple concurrent, non-concurrent, and/or cascading hazard scenarios. The requisite FOS should also be checked not only at the design stage, but also during the entire service life of the structural system. Thus, an integrated approach to achieve consistent multihazard load and resistance factors becomes the primary objective in order to analyse and design the structures and ensure the desired performance and safety of the engineered structural systems.

Relevant tools are required to optimize the design parameters of control devices to effectively function and mitigate the responses under a series of multiple-hazard scenarios. For example, seismic isolation system is a widely accepted technique in structural earthquake engineering employed for significantly increasing the flexibility and reducing the seismic forces in the superstructure. Due to increase in flexibility, there is a relative shift in the fundamental frequency of the system, which may now likely be prone to dynamic wind excitation and may have a comparable increase in the forces (demand). In such cases, the isolation system that was primarily used for design-basis earthquakes, may show worsening characteristics under wind loads, particularly the ambient ones ${ }^{28}$, apart from extreme windstorm as a design wind load. Therefore, maximizing the reduction in response under both earthquakes and winds should be of an utmost priority in order to develop multi-hazard resilient infrastructure, particularly for the lifeline structures. Moreover, for strategically important infrastructure, which might fall prey to acts of fanatism, the effects under the blast-induced ground motion (BIGM) need to be evaluated. The dynamic response of a building under earthquake ground excitation is considerably different than that under BIGM $^{29}$. Hence, it is pertinent to calibrate and optimize the design parameters of any response modification/control devices used in structure and infrastructure systems to achieve reliable performance under multi-hazard scenarios.

\section{Recommendations}

In every commercial software, steps pertaining to the design of any structure until load assignment remain almost the same in any case, which includes definition of geometry and material properties assigned to the members, adding support/boundary conditions, and applying loads and their combinations. The multi-hazard design step is hereby proposed to augment the current design method that follows load combinations of hazards (e.g. worst case combination of deal load, live load and extreme load, e.g. earthquake load). After this step, the design will also be based on site-specific (e.g. earthquake and wind, earthquake and flood) or scenario-specific conditions (e.g. post-blast fire). The subsequent steps are recommended to include lifecycle degradation (ageing) in the material properties due to (a) various effects/agents (e.g. corrosion of steel reinforcement/members), and (b) minor damage induced and accumulated because of small tremors, ambient winds, dynamic effects because of surrounding excitations such as those arising from train/vehicular movements. The design-level extreme events may occur anytime and in any order during specified service life of the structure, wherein the degraded structure with appropriate material (resistance) factors would be exposed to the loading event. Hence, the lifecycle FOS is evaluated in the next step in the design of structures by considering probabilistic multi-hazard scenarios with appropriate load factors. Figure 4 highlights the basic differences between the conventional and existing structural analysis and design with the multi-hazard design suitably incorporated. Augmentation of multi-hazard analysis and design in the conventional design approach for structure and infrastructure systems is shown, which is a decisive step ahead of the conventional analysis and design technique. A typical example has been discussed here to derive FOS under post-blast fire scenario. Finally, design iterations need to 

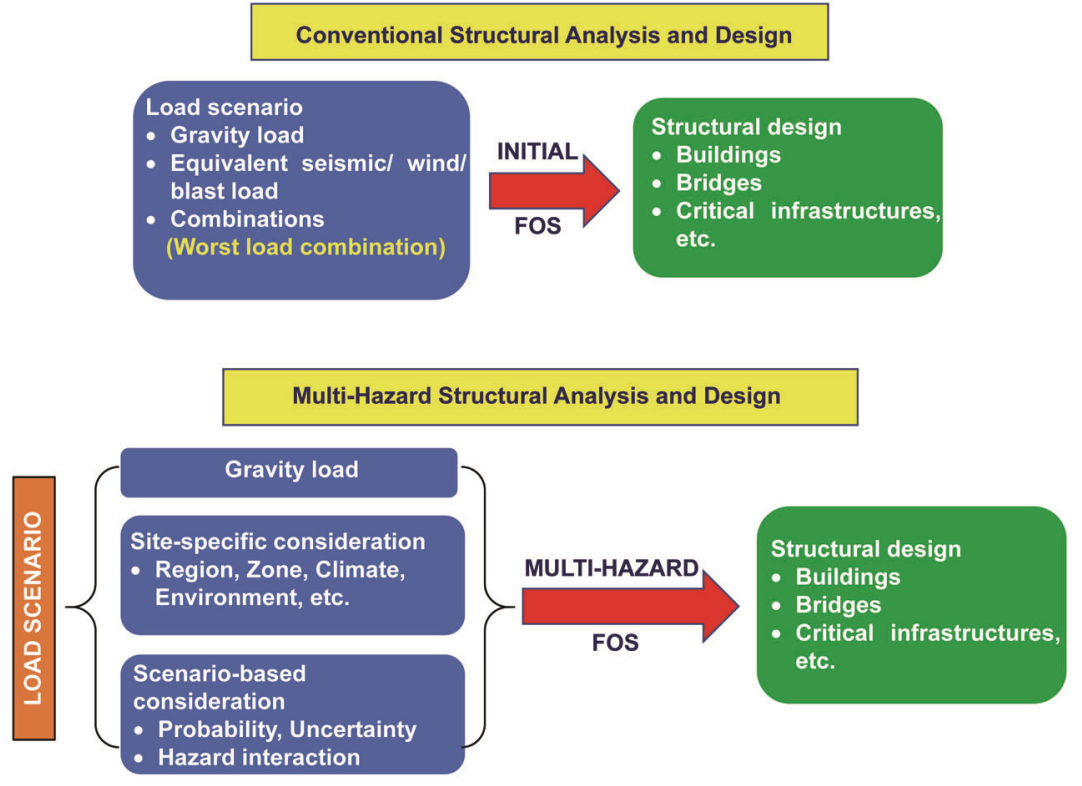

Figure 4. Schematic to highlight augmentation of multi-hazard analysis and design in the conventional design approach for structure and infrastructure systems.

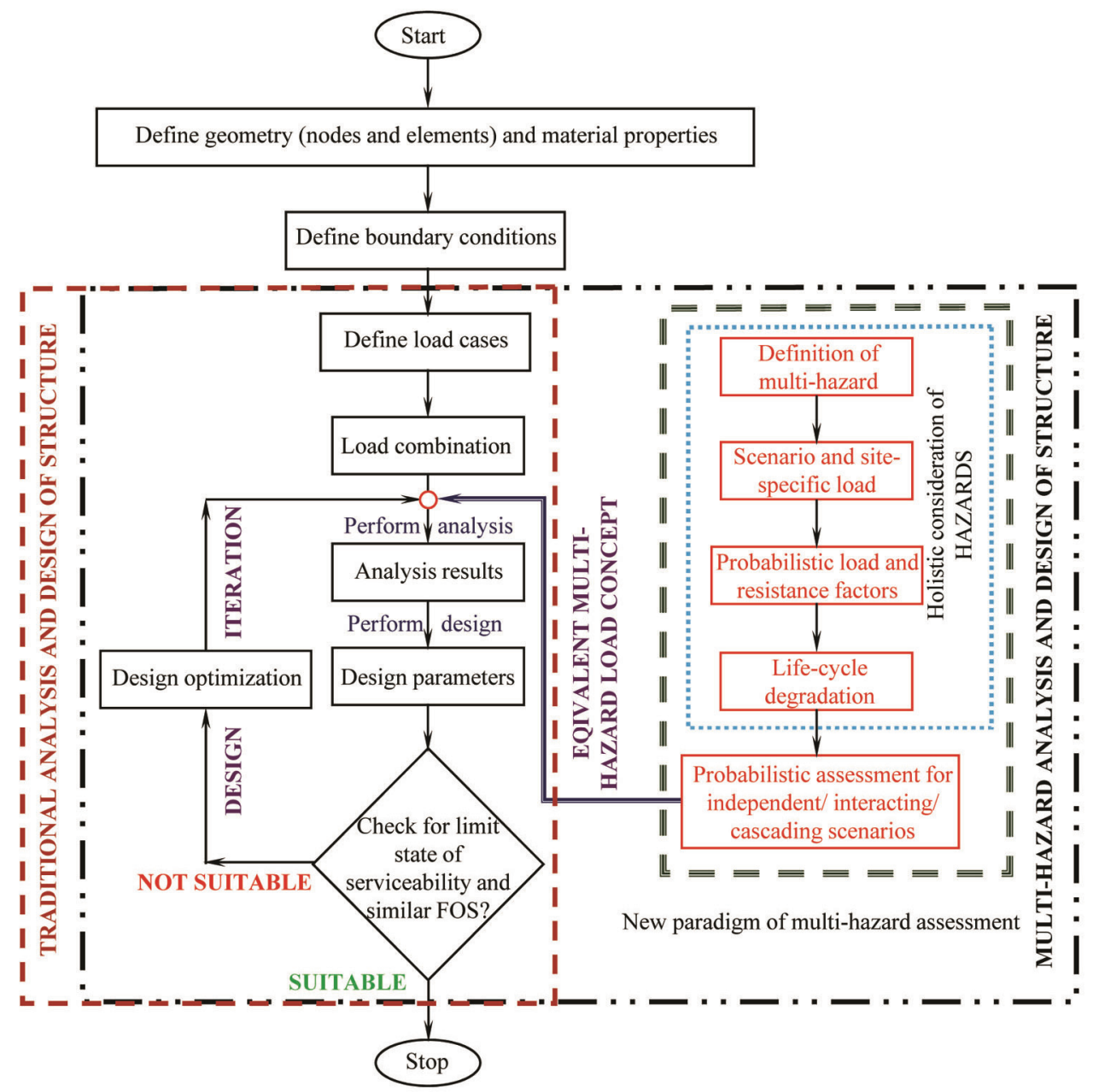

Figure 5. Proposed generalized multi-hazard analysis and design technique for structures and infrastructure systems. 
GENERAL ARTICLES

\begin{tabular}{|c|c|c|c|c|}
\hline \multirow[b]{2}{*}{ State } & \multicolumn{4}{|c|}{ Districts having substantial multi-hazard regions } \\
\hline & Earthquake and flood & Cyclone and flood & $\begin{array}{l}\text { Earthquake, cyclone and } \\
\text { flood }\end{array}$ & Earthquake and cyclone \\
\hline $\begin{array}{l}\text { Andhra Pradesh } \\
\text { and Telengana }\end{array}$ & $\begin{array}{l}\text { Adilabad, Karim Nagar, } \\
\text { Khammaam }\end{array}$ & $\begin{array}{l}\text { Krishna, Nellore, Srikakulam, } \\
\text { Visakhapatnam, } \\
\text { Vizianagram }\end{array}$ & $\begin{array}{l}\text { East Godavari, Guntur, } \\
\text { Prakasam, } \\
\text { West Godawari }\end{array}$ & - \\
\hline Assam & $\begin{array}{l}\text { All } 22 \text { districts listed in } \\
\text { Appendix } 2 \text { with flooding }\end{array}$ & $\begin{array}{l}\text { No cyclones, but speed can be } \\
50 \mathrm{~m} / \mathrm{s} \text { in the districts of } \\
\text { Appendix } 2 \text { causing local } \\
\text { damage, except Dhubri }\end{array}$ & - & - \\
\hline Bihar & $\begin{array}{l}\text { All } 25 \text { districts listed in } \\
\text { Appendix } 2\end{array}$ & - & - & - \\
\hline Goa & - & - & - & North and South Goa \\
\hline Gujarat & $\begin{array}{l}\text { Banaskantha, Danthe GS, } \\
\text { Gandhinagar, Kheda, } \\
\text { Mahesana, Panchmahals, } \\
\text { Vadodara }\end{array}$ & - & $\begin{array}{l}\text { Ahmedabad, Bharuch, } \\
\text { Surat, Valsad }\end{array}$ & $\begin{array}{r}\text { Amreli, Bhavnagar, } \\
\text { Jamnagar, Rajkot, } \\
\text { Junagad, Kachcha }\end{array}$ \\
\hline Haryana & $\begin{array}{l}\text { All eight districts listed in } \\
\text { Appendix } 2\end{array}$ & - & - & - \\
\hline Kerala & $\begin{array}{l}\text { Idukki, Kottayam, Palakkad, } \\
\text { Pathanamthitta }\end{array}$ & - & $\begin{array}{l}\text { Alappuzha, Ernakulum, } \\
\text { Kannur, Kasargod, } \\
\text { Kollam, Kozhikode, } \\
\text { Malappuram, } \\
\text { Thiruvananthapuram, } \\
\text { Thrissur }\end{array}$ & - \\
\hline Maharashtra & - & - & - & $\begin{array}{l}\text { Mumbai, Rayagad, } \\
\text { Ratnagiri, Sindhudurg, } \\
\text { Thane }\end{array}$ \\
\hline Odisha & - & Ganjam & Baleshwar, Cuttack, Puri & Dhenkanal \\
\hline Punjab & All 12 districts listed in Appendix 2 & - & - & - \\
\hline $\begin{array}{l}\text { Uttar Pradesh and } \\
\text { Uttarakhand }\end{array}$ & $\begin{array}{l}\text { All } 50 \text { districts listed in } \\
\text { Appendix } 2\end{array}$ & - & - & - \\
\hline West Bengal & $\begin{array}{l}\text { Birbhum, Darjeeling, Jalpaiguri, } \\
\text { Cooch Behar, Malda, } \\
\text { Murshidabad, } \\
\text { West Dinajpur }\end{array}$ & - & $\begin{array}{l}\text { Bardhaman, Kolkata, Hugli, } \\
\text { Howrah, Midnapore, } \\
\text { Nadia, North and South } \\
24 \text { Parganas }\end{array}$ & Bankura \\
\hline Union Territories & Delhi & - & Yanam (Puducherry) & Diu \\
\hline India & 139 districts & 6 districts & 29 districts & 16 districts \\
\hline
\end{tabular}

be performed using the multi-hazard loading scenarios pertinent to the concerned structure in order to optimize the member design. Such design philosophy may be initially implemented on critical structures, primarily where technology and economy should not be a barrier. Figure 5 shows the proposed multi-hazard analysis and design framework that is required to be implemented to achieve a resilient/robust built environment. In this framework, holistic consideration of the multi-hazard scenarios has been specifically addressed with implementation of the multi-hazard lifecycle FOS. Also, over a period of time, as research on multi-hazard analysis and design of structures progresses ahead, the prescriptive recommendations shall be replaced by engineered approaches. Nevertheless, the following are some prescriptive guidelines proposed for addressing the multi-hazard effects on structures.

\section{Multi-hazard design guidelines for building structures}

(a) Strategically important buildings must be checked for their desired safety under possible multi- hazard scenarios of post-earthquake fire, scenario-based blast and fire, and similar consequences of extreme events on a case-to-case basis, in addition to the conventional load combinations. Thereby, site-specific and scenario-based multi-hazard analysis and design of important buildings is recommended.

(b) Modal frequencies of important buildings must be compared with the frequency content of dynamic excitation and design for such multi-hazard scenarios must cater to the amplified response under the excitations anticipated. 
Appendix 2. Multi-hazard prone districts ${ }^{4}$

Assam

Barpeta, Bongaigaon, Cachar ${ }^{\mathrm{a}}$, Darrang, Dhemaji, Dhuburi, Dibrugarh, Goalpara, Golaghat, Hailaknadi ${ }^{a}$, Jorhat, Kamrup, Karbianglong, Karimganj ${ }^{\text {a }, ~ K o k r a j h a r, ~ L a k h i m p u r, ~ M o r i g a o n, ~ N a g a o n, ~}$ Nalbari, Sibsagar, Sonitpur, Tinsukia.

Bihar $^{\mathrm{b}}$

Araria, Begusarai, Bhagalpur, Bhojpur, Darbhanga, Gopalganj, Katihar, Khagaria, Kishanganj, Madhepura, Madhubani, Munger, Muzaffarpur, Nalanda, Nawada, Paschim Champaran, Patna, Purbachamparan, Purnia, Samastipur, Saran, Saharsa, Sitamarhi, Siwan, Vaishali.

Haryana $^{c}$

Ambala, Bhiwani, Faridabad, Gurgaon, Hisar, Jind, Kurukshetra, Rohtak.

Punjab $^{\mathrm{d}}$

Amritsar, Bathinda, Faridkot, Firozpur, Gurdaspur, Hoshiarpur, Jalandhar, Kapurthala, Ludhiana, Patiala, Rupnagar, Sangrur.

Utar Pradesh and Uttarakhand

Agra, Aligarh, Allahabad, Azamgarh, Bahraich, Ballia, Barabanki, Bareilly, Basti, Bijnor, Budaun, Bulandshahr, Deoria, Etah, Etawah, Faizabad, Farrukhabad, Fatehpur, Firozabad, Ghaziabad, Ghazipur, Gonda, Gorakhpur, Hardoi, Haridwar, Jaunpur, Kanpur (Dehat), Kanpur (Nagar), Kheri, Lucknow, Maharajganj, Mainpuri, Mathura, Mau, Meerut, Mirzapur, Moradabad, Muzaffarnagar, Nainital, Pilibhit, Partapgarh, Raebareli, Rampur, Saharanpur, Shahjahanpur, Siddarth Nagar, Sitapur, Sultanpur, Unnao, Varanasi

${ }^{\text {a }}$ Districts liable to cyclonic storm but no storm surge.

${ }^{\mathrm{b}-\mathrm{e}}$ No cyclonic storm.

(c) Considering degradation in material properties over the service life of a structure, the lifecycle capacity-todemand ratio must be calculated; and, strengthening schemes at different times during the service life need to be made part of the design process for maintaining the ratio as specified at the design stage.

(d) FOS of buildings intended at the design stage must be ensured to nearly remain the same during their entire service life, duly accounting for periodic maintenance schedule, retrofitting as well as rehabilitation and restoration activities undertaken after any extreme event.

(e) Response modification/control devices, if employed for structural protection in avoiding of loss of life and property, must be designed based on site-specific conditions and probability of occurrence of earthquakes, windstorms, and other hazards involving dynamic excitation.

(f) Residual capacity of the response control devices under extreme multi-hazard scenarios of dynamic excitation such as those arising from earthquakes and gusty winds must be studied at the end of each event to ensure their readiness and effectiveness for the next probable event or their need for replacement.

(g) Reassessment of the structural design after an extreme event must be conducted with predicted in situ material properties to verify adequate safety of the structure under the events probable subsequently.

(h) Until the IS for multi-hazard design strategy remains under formulation and specific design guidelines become available, the standard literature should be consulted for analysis, design, detailing and maintenance of important buildings under multi-hazard scenarios of earthquake, windstorm, blast, fire, and such extreme events that the building may be exposed to during its design (service) life.

\section{Multi-hazard design guidelines for bridge structures}

In addition to those mentioned earlier in the text, the following are additional guidelines for bridge design. (a) Flood scouring in bridge design must be treated as an extreme event; and the scour calculations must be based on return period of flood discharge in a region of particular interest. (b) Critical scour depth is necessary in design calculations under a design flood event.

\section{Summary}

In contrast to traditional design approach, multi-hazard engineering is an emerging field focusing on holistic approach to identify the risks in disaster-prone countries such as India for sustainable infrastructure development. The multi-hazard assessment is relatively unusual and rather challenging compared to the traditional structural analysis and design, wherein the design objectives focus on achieving similar FOS under perceived multiple hazards. A unified design approach is necessary to achieve coherent load and resistance factors for designing structures under multi-hazard risks. Optimized structural design should be derived through 'multi-hazard lifecycle engineering' that considers the degradation which occurred in the structural system in the entire design (service) life under various loading conditions and environmental effects of ageing. The guidelines are not envisioned to overcomplicate or transform the current design strategies, which might not be easily adopted by the present engineering community and design should not become cost-prohibitive to realize in real-life constructions. Finally, significant research efforts are required on multihazard analysis and design of structures, particularly in the Indian context where several states are prone to their effects, to ensure life safety and avert economic losses.

1. National Institute of Disaster Management, East Asia Summit (NIDM-EAS), New Delhi 2014; https://nidm.gov.in/easindia2014/ err/pdf/country_profile/India.pdf.

2. NDMA, National Disaster Management Plan, A publication of the National Disaster Management Authority, Government of India, 2019; https://ndma.gov.in/sites/default/files/PDF/ndmp-2019.pdf

3. India Risk Survey, 2017; http://ficci.in/Sedocument/20416/IndiaRisk-Survey-2017-Report.pdf (accessed on 20 February 2021). 
4. BIS, National building code of India. Bureau of Indian Standard, New Delhi, 2016; http://www.bis.org.in/sf/nbc.htm

5. Kale, V. S., Landscapes and Landforms of India. In World Geomorphological Landscapes, Springer, 2014, pp. 1-271.

6. BIS, IS 1893 - Part 1 , Criteria for earthquake resistant design of structures - Part 1: general provisions and buildings. Bureau of Indian Standard (BIS), New Delhi, 2016, pp. 1-29.

7. Roy, T. and Matsagar, V., Effectiveness of passive response control devices in buildings under earthquake and wind during design life. Struct. Infrastruct. Eng., 2019, 15(2), 252-268; https://doi.org/10.1080/15732479.2018.1547768.

8. Roy, T. and Matsagar, V., Probabilistic assessment of steel buildings installed with passive control devices under multi-hazard scenario of earthquake and wind. Struct. Saf., 2020, 85, article number 101955; https://doi.org/10.1016/j.strusafe.2020.101955.

9. Malhotra, A., Roy, T. and Matsagar, V., Effectiveness of friction dampers in seismic and wind response control of connected adjacent steel buildings. Shock Vibr. (Spec. Issue), 2020, Article ID 8304359; https://doi.org/10.1155/2020/8304359.

10. BIS, IS 1893 - Part 3, Criteria for earthquake resistant design of structures - Part 3: bridges and retaining walls, Bureau of Indian Standard (BIS), New Delhi, 2014, pp. 1-29.

11. IRS Concrete Bridge Code, Code of practice for plain, reinforced and prestressed concrete for general bridge construction. Indian Railway Standard, Research Designs and Standards Organization, Railway Board, Ministry of Railways, Government of India, 1997.

12. IRC: 24 , Standard specifications and code of practice for road bridges, section-V: steel road bridges (Limit State Method). Indian Roads Congress, New Delhi, 2010

13. IRC: 112, Code of practice for concrete road bridges, Indian Roads Congress, New Delhi, 2011.

14. IRC: 6, Standard specifications and code of practice for road bridges, section-II: loads and load combinations. Indian Roads Congress, IRC Bhawan, India, 2017.

15. IRS Steel Bridge Code (SBC), Code of practice for the design of steel or wrought iron bridges carrying rail, road or pedestrian traffic, Indian Railway Standard, Research Designs and Standards Organization, 2019, Ministry of Railways, Government of India, 2019.

16. Kim, I., Fard, M. Y. and Chattopadhyay, A., Investigation of a bridge pier scour prediction model for safe design and inspection, J. Bridge Eng., 2015, 20(6), article number 04014088.

17. Song, S.-T., Wang, C.-Y. and Huang, W.-H., Earthquake damage potential and critical scour depth of bridges exposed to flood and seismic hazards under lateral seismic loads. Earthq. Eng. Eng. Vibr., 2015, 14(4), 579-594.
18. Sun, Y. et al., Damage effect of steel circular tube subjected to fire and blast. J. Construct. Steel Res., 2021, 176, article number 106389

19. Fabry, N., Guesdon, M., D'Aló, G. and Cros, E., Stay cable hardening: new developments on blast, fire and ice protection. In FIB 2018 - Proceedings for the 2018 FIB Congress: Better, Smarter, Stronger, Melbourne, Australia, 2019, pp. 2879-2890.

20. BIS, IS 6922, Criteria for safety and design of structures subjected to underground blasts. Bureau of Indian Standard, New Delhi, 2003, pp. 1-13.

21. BIS, IS 4991, Criteria for blast resistant design of structures for explosions above ground. Bureau of Indian Standard, New Delhi, India, 2003, pp. 1-38.

22. Roy, T. and Matsagar, V., Fire fragility of reinforced concrete panels under compressive in-plane and transverse out-of-plane loads. Fire Saf. J., 2020, 113, article number 102976; https://doi.org/10.1016/j.firesaf.2020.102976.

23. Behnam, B. and Ronagh, H., An engineering solution to improve post-earthquake fire resistance in important reinforced concrete structures, Adv. Struct. Eng., 2014, 17(7), 993-1009.

24. BIS, IS 456, Plain and reinforced concrete - code of practice. Bureau of Indian Standard, New Delhi, 2000.

25. HAZUS MH MR1, Multi-Hazard Loss Estimation Methodology: Technical Manual, Federal Emergency Management Agency, Washington, DC, USA, 2003.

26. Duthinh, D. and Simiu, E., Safety of structures in strong winds and earthquakes: multi-hazard considerations. J. Struct. Eng. (ASCE), 2010, 136(3), 330-333.

27. Huang, C., Shen, J. J., Zhou, M. and Lee, G. C., Force-based and displacement-based reliability assessment approaches for highway bridges under multiple hazard actions. J. Traffic Transp. Eng., 2015, 2(4), 223-232.

28. Roy, T., Saito, T. and Matsagar, V., Multi-hazard framework for investigating high-rise base-isolated buildings under earthquakes and long duration winds. Earthq. Eng. Struct. Dyn., 2021, 50(5), 1334-1357; https://doi.org/10.1002/eqe.3401.

29. Zelleke, D. H., Saha, S. K. and Matsagar, V., Multi-hazard response control of base-isolated buildings under bidirectional dynamic excitation. Shock Vibr. (Spec. Issue), 2020, article ID 8830460; https://doi.org/10.1155/2020/8830460.

30. Bach, C., Gupta, A. K., Nair, S. S. and Birkmann, J., Critical infrastructure and disaster risk reduction. National Institute of Disaster Management, 2014, pp. 1-62.

Received 21 November 2020; revised accepted 15 March 2021

doi: $10.18520 / \mathrm{cs} / \mathrm{v} 121 / \mathrm{i} 1 / 44-55$ 